\title{
Trabalho pedagógico: dimensões e possibilidade de práxis pedagógica
}

\author{
Rodrigo Cardozo Fuentes* \\ Liliana Soares Ferreira**
}

\section{Resumo}

Este texto objetiva articular e sistematizar argumentos e elaborações de sentidos sobre trabalho pedagógico, apresentando um modelo multidimensional que, nessa perspectiva, pensa-se que pode melhor explicitar esta categoria. Partiu-se de um conceito de pedagógico como o trabalho relacionado ao campo da Pedagogia que objetiva a produção do conhecimento. Com base nesse conceito amplo, foram elaboradas subcategorias, índices e estabelecidas relações entre eles. Obteve-se, então, sentidos menores, que, articulados entre si, garantem uma reelaboração conceitual mais ampla. Esta sequência metodológica assemelha-se ao percurso de escrita deste texto: parte-se da descrição de entendimentos de trabalho pedagógico, a partir de um modelo contendo dimensões deste trabalho específico e suas articulações, e, com base nessa multidimensionalidade, apresenta-se outra, que se entende mais elaborada como conceituação de trabalho pedagógico, aproximando-o da práxis pedagógica, tendo a escola como contexto.

Palavras-chave: Trabalho pedagógico. Práxis pedagógica. Escola.

\footnotetext{
* Doutor em Educação pela Universidade Federal de Santa Maria (UFSM). Professor Colaborador do Programa de Pósgraduação em Educação Profissional e Tecnológica da Universidade Federal de Santa Maria (UFSM).

** Doutora em Educação pela Universidade Federal do Rio Grande do Sul (UFRGS). Professora do Departamento de Fundamentos da Educação da Universidade Federal de Santa Maria (UFSM).
} 


\section{Introdução}

Há uma recorrente referência ao trabalho pedagógico na literatura e nos discursos sobre educação. Entretanto, ao analisar essas referências, observa-se certa superficialidade acerca dos sentidos de trabalho pedagógico como categoria central, quando se debate sobre quem são os professores e qual o trabalho que realizam. Observa-se também certa minimização dos sentidos de trabalho pedagógico, prática pedagógica, didática e atividade, parecendo indicar que se trata de categorias cujos sentidos se substituem. A aproximação mais evidente é entre trabalho pedagógico e prática pedagógica, tratados como sinônimos e poucas vezes diferenciados. Porém, sobretudo na escola, ao reduzir-se o trabalho dos professores à prática, arrefece-se a capacidade transformadora dos sujeitos em si e a partir de si. Nesse sentido, a opção por prática consome significativamente o aspecto ontológico contido na categoria trabalho, e, nesse caso, se o trabalho pedagógico é empregado como sinônimo de prática pedagógica, os trabalhadores parecem ter possibilidades menores de se autoproduzirem no e a partir de seu trabalho. Desse modo, essa pouca ênfase e esclarecimento de sentidos sobre trabalho pedagógico, tratando-o não raramente como prática pedagógica, sem esclarecer a diferenciação, impossibilita pensar-se em um estágio além, o de práxis pedagógica, o que implicaria a sua integralização como unidade da teoria e da prática.

Diferentemente, parte-se do pressuposto que o trabalho dos professores é trabalho pedagógico, uma produção que implica a relação com outros sujeitos. Assim exposto, conserva o caráter ontológico, mas o sentido de pedagógico pode ainda ficar minimizado, pois este se potencializa quando está em conexão com um projeto pedagógico, ou seja, quando compõe um projeto efetivo pelo qual o sujeito age em relação ao mundo, transformando-o e transformando-se. Caso seja diferente, como já se afirmou, esse trabalho reduz-se ao nível da prática pedagógica tão somente.

Com o objetivo de apresentar, articular e sistematizar argumentos e elaborações de sentidos de trabalho pedagógico até agora possíveis, neste artigo, apresenta-se um modelo multidimensional que, nessa perspectiva, pensa-se que pode melhor explicitar sentidos para esta categoria. Chegou-se a essas elaborações partindo-se de uma conceituação genérica de trabalho pedagógico: 
Por trabalho pedagógico entende-se todo o trabalho cujas bases estejam, de alguma forma, relacionadas à Pedagogia, evidenciando, portanto, métodos, técnicas, avaliação intencionalmente planejadas e tendo em vista o alcance de objetivos relativos à produção de conhecimentos. (FERREIRA, 2010, online).

Com base nesse sentido genérico, foram selecionadas subcategorias e índices e também estabelecidas relações entre eles. Obteve-se, então, sentidos menores, que, articulados entre si, garantem uma reelaboração conceitual mais ampla. Esta sequência metodológica assemelha-se ao percurso de escrita deste texto: parte da descrição de entendimentos de trabalho pedagógico, a partir de um modelo contendo dimensões deste trabalho específico e suas articulações, e, com base nessa multidimensionalidade, apresenta outra, que se entende mais elaborada, como conceituação de trabalho pedagógico, aproximando-o de práxis pedagógica e tendo a escola como contexto.

Apresenta-se o trabalho pedagógico como categoria que sintetiza aspectos que têm por base os seguintes pressupostos: a) é trabalho e como tal denota características ontológicas e históricas; b) envolve o trabalho de profissionais da educação e de estudantes, portanto sua produção é relativa sempre a um determinado grupo de sujeitos; c) é pedagógico, portanto especificamente orientado a um processo de produção de conhecimentos; d) é intencional, tem objetivos definidos em sua sociabilidade, então, é político. Em processo metodológico de elaboração de índices, categorias, desconstrução e reconstrução de sentidos, considerando-se esses pressupostos, configuraram-se modos discursivos para descrever trabalho pedagógico multidimensionalmente, de maneira que cada dimensão corresponda a um conjunto de sentidos agrupados por suas características e correspondências intrínsecas. Denomina-se cada modo discursivo de dimensão, exatamente para configurá-lo como parte de um todo: a concepção de trabalho pedagógico. Assim, a categoria trabalho pedagógico passa a ser descrita com base em quatro dimensões, quais sejam: histórico-ontológica; pedagógica; social e éticopolítica. Cada dimensão opera na particularidade dos seus sentidos, e a articulação entre elas produz a compreensão do todo, portanto produz a categoria trabalho pedagógico como concepção. Para ilustrar, objetivando tornar mais clara a exposição, desenvolveu-se uma representação gráfica que auxilia na compreensão de cada modo discursivo proposto e de suas inter-relações, conforme apresentado na Figura 1: 
Figura 1 - Representação gráfica do trabalho pedagógico e suas quatro dimen sões

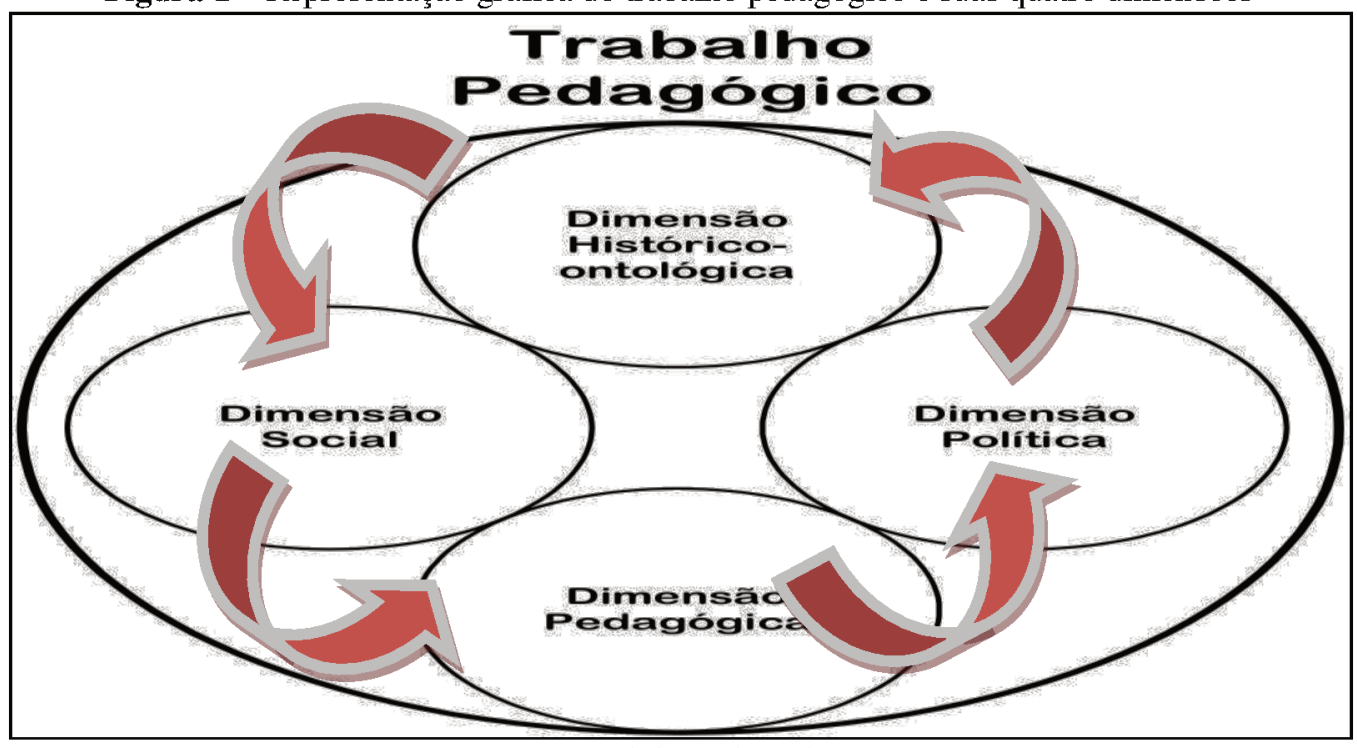

Fonte: elaborada pelos autores.

Compreendendo-se o sentido dinâmico presente em cada dimensão, revela-se o que há de unitário no trabalho pedagógico, ainda que efetivado em níveis ou modalidades educacionais diferenciadas. $\mathrm{O}$ modelo multidimensional proposto permite uma análise da categoria, evidenciando ou diferenciando o trabalho pedagógico pela maior ou menor ênfase em alguma(s) de suas dimensões. Em suma, o que caracteriza o trabalho pedagógico na Educação Infantil e o diferencia do trabalho pedagógico na Educação Profissional, por exemplo, é a primazia de uma ou mais dimensões em relação às outras. É o que se descreverá a seguir, apresentando-se cada dimensão para, após, reuni-las novamente em uma concepção unitária. Para tanto, dada a perspectiva dialética do trabalho, apoiar-se-á os argumentos em autores que balizam suas proposições teóricas no texto marxiano, estabelecendo-se assim um compósito teórico crítico sobre o qual se assentam as proposições que caracterizam a abordagem ora apresentada.

\section{0 trabalho pedagógico em suas dimensões}

A seguir, descreve-se cada dimensão para, na próxima seção, argumentar-se sobre se entende a articulação entre as quatro dimensões. Reitera-se que se acredita que as dimensões estão imbricadas, interligadas, e, assim, como totalidade, indicam os critérios para a conceituação de trabalho pedagógico, tendo como referência o conceito de práxis pedagógica. 


\subsection{Dimensão histórico-ontológica}

Para compreender o significado de trabalho pedagógico em sua dimensão histórico-ontológica, tem-se por subsídio o entendimento do conceito de trabalho haurido nas obras de Karl Marx, sobretudo em $O$ capital $(1996,2013)$. Nessa obra, o trabalho é descrito como ação intencional, propriamente humana, com o objetivo de transformar a natureza e propiciar a existência material dos seres. Como revela Marx (1996, p. 297), o ser humano “se defronta com a matéria natural [...], põe em movimento as forças naturais pertencentes a sua corporalidade [...], a fim de apropriar-se da matéria natural numa forma útil para sua própria vida". É a partir do trabalho que o ser humano revela as suas habilidades, se distingue do animal, transforma e é transformado: "Ao atuar, por meio desse movimento, sobre a Natureza externa a ele e ao modificá-la, ele modifica, ao mesmo tempo, sua própria natureza. Ele desenvolve as potências nela adormecidas e sujeita o jogo de suas forças a seu próprio domínio." (MARX, 1996, p. 297).

Em suas características peculiares, o trabalho pedagógico realizado pelos professores distinguese do trabalho dos operários na fábrica, por não produzir objetiva e diretamente uma mercadoria. Marx (2013), na obra $O$ capital, classifica esse tipo de trabalho como imaterial ou mesmo trabalho improdutivo, explicando que ele se caracteriza por utilizar e exercitar os aspectos cognitivos mais elevados, exigindo as elaborações humanas mais complexas, abstratas e sem relação direta com a geração de mais-valia.

Considera-se também que o trabalho pedagógico deve ser entendido em sua perspectiva educativa, de formação de consciência, de socialização de conhecimento, de aperfeiçoamento, de humanização, ao encontro dos fundamentos histórico-ontológicos da relação trabalho-educação. Históricos, porque são decorrentes de um processo dialético desenvolvido ao longo do tempo e da ação dos próprios homens. Ontológicos, porque o resultado dessa interação é a constituição dos seres humanos como propriamente humanos. Saviani (2007) explica o elo entre trabalho e a sua dimensão educativa da seguinte forma:

Se a existência humana não é garantida pela natureza, não é uma dádiva natural, mas tem de ser produzida pelos próprios homens, sendo, pois, um produto do trabalho, isso significa que o homem não nasce homem. Ele forma-se homem. Ele não nasce sabendo produzir-se como homem. Ele necessita aprender a ser homem, precisa aprender a produzir sua própria existência. Portanto, a produção do homem é, ao mesmo tempo, a formação do homem, isto é, um processo educativo. A origem da educação coincide, então, com a origem do homem mesmo. (SAVIANI, 2007, p. 154, grifos nossos). 
A dimensão histórico-ontológica se expande a partir do domínio e da realização consciente do trabalho, opondo-se frontalmente ao sentido de trabalho alienado ou trabalho estranhado, como referese Marx (2008, p. 85): "quando arranca do homem o objeto de sua produção, o trabalho estranhado arranca-lhe sua vida genérica, sua efetiva objetividade genérica" (MARX, 2008, p. 85). Assim, a dimensão histórico-ontológica é indispensável na categoria trabalho pedagógico, pois carrega em sua gênese toda a carga de sentidos e significados próprios do trabalho em si mesmo. Independentemente do nível, escola ou modalidade em que é realizado o trabalho pedagógico, por ser pedagógico, ele evidencia a dimensão histórico-ontológica, constitutiva e prospectiva desse modo de trabalho.

\subsection{Dimensão pedagógica}

A dimensão pedagógica é a que incorpora ao trabalho os aspectos teóricos e filosóficos, alinhando-os e articulando-os com foco na sua finalidade especifica, ou seja, na produção do conhecimento. É a que promove a fluidez, aponta a direção e dissipa as tensões relativas à especificidade do trabalho em educação.

Por isso, é a dimensão que demarca e caracteriza o trabalho quanto aos seus aspectos intencionais na produção do conhecimento. Não é prática pedagógica, por estar imbricada em um projeto pedagógico, individual e coletivo; ou didática, pois envolve a Pedagogia como um todo. Vai além, portanto, objetiva intencional e prioritariamente a superação da dicotomia entre teoria e prática. É o trabalho pedagógico fundamentado e fundamentando uma teoria pedagógica. Trata-se do meio e do modo pelo qual sistematicamente é organizado o trabalho pedagógico com a intencionalidade de produzir autonomia intelectual. Como tal, sua base epistêmica é a Pedagogia entendida como práxis, o que implica a conexão entre o trabalho e uma perspectiva teórica. Saviani (2010) argumenta sobre a compreensão de Pedagogia como teoria que orienta o trabalho em educação:

[...] o conceito de pedagogia reporta-se a uma teoria que se estrutura a partir e em função da prática educativa. A pedagogia, como teoria da educação, busca equacionar, de alguma maneira, o problema da relação educador-educando, de modo geral, ou, no caso específico da escola, a relação professor-aluno, orientando o processo de ensino e aprendizagem. Assim, não se constituem como pedagogia aquelas teorias que analisam a educação pelo aspecto de sua relação com a sociedade, não sem o objetivo de formular diretrizes que orientem a atividade educativa. (SAVIANI, 2010, p. 401).

A dimensão pedagógica efetiva-se com a centralidade no trabalho dos professores, mas não com a exclusividade de seu trabalho. Essa dimensão caracteriza o trabalho de múltiplos profissionais da educação, no mesmo sentido evidenciado por Freitas (1992), no qual o profissional da educação é um 
sujeito em condições de realizar relações pedagógicas tanto na escola quanto para além dela. Então “[...] Não há que se identificar, aqui, trabalho pedagógico com docência - esta é apenas uma das formas de se desenvolver o trabalho pedagógico e um dos aspectos da atuação do profissional da educação." (FREITAS, 1992, p. 8). Cabe ainda reiterar que nem todo o trabalho dos profissionais em educação é pedagógico. Ferreira (2008) propõe a seguinte compreensão de pedagógico:

Pedagógico é todo o pensar-agir da escola com o intuito de produzir conhecimento. Porém, não é pedagógico o pensar-agir, embora muito bem organizado, incoerente com a expectativa de produção do conhecimento dos sujeitos da aula. Percebe-se, então, não haver como dissociar uma concepção de pedagógico do espaço, do tempo e do trabalho realizado pela escola. Pedagógico é a articulação desses fatores, objetivando a produção do conhecimento. Afinal, se os sujeitos estudantes ingressam na escola é porque intencionam aprender. E aprender é um complexo movimento de linguagens em interlocução, subjetividades em interação e historicidades que se entrelaçam, no intuito de ampliar as compreensões de mundo, inserirem-se, cada vez mais, na cultura e "genteificar-se"1 ainda mais. (FERREIRA, 2008, p. 178).

A dimensão pedagógica, assim, desenvolve-se a partir da filiação objetiva a uma determinada teoria pedagógica, ou seja, um trabalho organizado e estruturado segundo uma base teórica apropriada. A expressão do sentido pedagógico pode ser formalmente configurada a partir de um projeto pedagógico institucional, que, segundo Veiga (2003, p. 275), consiste em um coletivo modo de "[...] integrar ações dispersas, criar sinergias no sentido de buscar soluções alternativas para diferentes momentos do trabalho pedagógico-administrativo". Desse modo, é possível, também, pertencer, mobilizar esforços, com o objetivo de alcançar o que é interesse comum e "[...] fortalecer a construção de uma coerência comum, mas indispensável, para que a ação coletiva produza seus efeitos" (VEIGA, 2003, p. 275).

Os professores podem desenvolver um projeto pedagógico individual que lhes orientará em seu trabalho, assegurando, deste modo, a unidade entre teoria e seu trabalho. Tal projeto é sempre oriundo de movimentos entre o geral e o particular e, então, constitui-se em síntese das crenças, propostas e possibilidades políticas dos professores, materializadas em seu trabalho. Constitui-se desde o processo de educação profissional dos professores para o trabalho, em cursos de graduação e pós-graduação, mas consolida-se no cotidiano escolar, na medida em que o projeto transforma-se em trabalho pedagógico. 


\subsection{Dimensão social}

A educação é social por excelência. O pedagógico também o é. Por esse motivo, é na dimensão social que os sujeitos efetivam o trabalho pedagógico, constituindo de fato o processo educativo. A teoria mescla-se com a prática e possibilita a transformação:

[...] a teoria em si não transforma o mundo. Pode contribuir para sua transformação, mas para isso tem de sair de si mesma e, em primeiro lugar, tem de ser assimilada pelos que hão de suscitar, com seus atos reais, efetivos, essa transformação. Entre a teoria e a atividade prática transformadora se insere um trabalho de educação das consciências, de organização dos meios materiais e planos concretos de ação; tudo isso como passo indispensável para desenvolver ações reais efetivas. Nesse sentido, uma teoria é pratica quando materializa, por meio de uma série de mediações, o que antes só existia idealmente, como conhecimento da realidade ou antecipação ideal de sua transformação. (VÁZQUEZ, 2011, p. 237).

E esses sujeitos, agora protagonistas do trabalho pedagógico, não são neutros nem destituídos de sua historicidade e de seus desejos. Estão imersos em um processo educativo cujos objetivos podem ainda se mostrar distantes, até mesmo utópicos, mas são seu ponto de partida. A dimensão social se expande a partir da produção de um trabalho pedagógico associado à prática social, reconhecendo e respeitando as realidades dos sujeitos. Saviani (2015) argumenta, com base na perspectiva da Pedagogia histórico-crítica, para a qual

[...] a educação é entendida como uma atividade mediadora no interior da prática social global. Como tal, o ponto de partida e o ponto de chegada da prática educativa é a prática social. Daí decorre um método que parte da prática social onde professor e aluno se encontram igualmente inseridos ocupando, porém, posições distintas, condição para que travem uma relação fecunda na compreensão e encaminhamento da solução dos problemas postos pela prática social, cabendo aos momentos intermediários do método identificar as questões suscitadas pela prática social (problematização), dispor os instrumentos teóricos e práticos para a sua compreensão e solução (instrumentação) e viabilizar sua incorporação como elementos integrantes da própria vida dos alunos (catarse). (SAVIANI, 2015, p. 35).

O trabalho pedagógico estabelecido a partir da prática social e do compromisso com as questões da humanização, da autonomia e do desenvolvimento do pensamento crítico potencializa a dimensão social, conduzindo à superação da educação unilateral, centrada apenas na formação para o "mercado de trabalho". 


\subsection{Dimensão política}

Na intenção de compreender a dimensão política, parte-se da palavra "política" que, em Chaui (2012), pode representar uma atividade específica realizada por um profissional específico, ou, em outro momento, uma ação coletiva reivindicatória específica dos membros da sociedade dirigida aos governantes ou ao próprio Estado. Entretanto, o conceito que mais se aproxima da dimensão em análise é o que define a política como relação entre as esferas individuais e coletivas no tocante à forma como se organiza o poder:

[...] o crescimento das atribuições conferidas aos governos, na forma do Estado, levou a uma ampliação do campo das atividades políticas, que passaram a abranger questões administrativas e organizacionais, decisões econômicas e serviços sociais. Essa ampliação das atribuições estatais acabou se estendendo para outras esferas da vida social, levando a um uso generalizado da palavra política para referir-se a toda modalidade de direção de grupos sociais que envolva poder, administração e organização, tanto no plano público como no plano privado. (CHAUI, 2012, p. 431).

Compreende-se que a dimensão política do trabalho pedagógico se estrutura a partir do sujeito, das relações de poder no interior do espaço educativo e em sua articulação com as relações de poder no plano social mais amplo. Não se pode desconsiderar, ainda, que a sociedade capitalista contém em seu interior interesses de classes antagônicos. Portanto as disputas de poder se fazem presentes, mesmo em formas dissimuladas. Em meio às disputas, cabe ao Estado a ação regulatória por efeito das políticas públicas. Na articulação desse sistema, a educação passa a ser um elemento modulador da cidadania política dos indivíduos, estabelecendo para os sujeitos uma forma socialmente aceitável no que concerne aos padrões de sociabilidade, produção e consumo.

Em se tratando de um país da periferia do capitalismo mundial, com espaço definido na divisão social do trabalho, a trajetória para a emancipação plena dos sujeitos torna-se uma tarefa desafiadora. A cidadania plena como um objetivo a ser perseguido e alcançado com o exercício amplo da dimensão política. A partir de um trabalho pedagógico multilateral, que promova o acesso ao amplo mundo do trabalho, desenvolvem-se as possibilidades de inclusão produtiva dos sujeitos, o acesso ao consumo e o exercício pleno da cidadania política e social.

A dimensão política do trabalho pedagógico tem a sua relevância mais explícita no período formativo profissional dos sujeitos, pelo qual se objetiva a inclusão no mundo do trabalho e a ampla participação nos planos político-sociais. 


\subsection{A articulação entre as quatro dimensões}

Segundo a Física clássica, o espaço pode ser descrito a partir da interação entre três dimensões, que definem a altura, largura e o comprimento dos objetos. Neste caso específico, o conceito de dimensão corresponde a um parâmetro utilizado para descrever o fenômeno observado. Para se compreender adequadamente o significado de espaço, deve-se, portanto, compreender-se cada uma de suas dimensões e o modo com o qual se organizam. Torna-se muito difícil conceituar espaço a partir de uma abordagem unidirecional, plasmada em um único sentido ou dimensão. A analogia aqui é válida. Descrever a complexidade da categoria trabalho pedagógico em um sentido linear deixa a impressão que "algo ficou fora" ou que a abordagem não integra a real imagem do "todo" que representa.

Esta forma discursiva de desenvolver a categoria trabalho pedagógico, com base em dimensões, como aqui apresentada, diferencia-se totalmente do sentido linear e da tentativa de estabelecer um conceito estático, estabilizado para a categoria. A análise multidimensional proposta contém em si mesma o movimento e a amplitude que a categoria requer. As quatro dimensões - histórico-ontológica, pedagógica, social e política - são independentes entre si e, se tomadas individualmente, não integralizam o sentido de "trabalho pedagógico", mas, ao ser articuladas entre si, tornam clara a perspectiva multidimensional do trabalho pedagógico.

A dimensão histórico-ontológica conecta-se epistemologicamente ao conceito de trabalho, diferenciando-se radicalmente de prática ou ação pedagógica; hipostasia-se no conceito marxiano de "trabalho" como elemento distintivo do gênero humano, portanto ontológico. Articula-se objetivamente com as dimensões social, política e pedagógica, pois é trabalho coletivo, social, transformador e educativo por natureza. Representa o domínio sobre o trabalho que produz a emancipação do sujeito em oposição ao trabalho alienado.

A dimensão social expressa o caráter coletivo, com centralidade no trabalho entre professores e estudantes. Integra um processo de trabalho que congrega o desejo dos estudantes por um "vir a ser" objetivo, vislumbrado através da educação formal. Constitui um processo de sociabilidade mais amplo, um caminho para a emancipação plena do sujeito. Articula-se ao pedagógico pelo caráter educativo/formativo do sujeito e à dimensão política pela aspiração de autonomia e cidadania plenas.

A dimensão pedagógica promove o caráter educativo do processo, apresentando-se como elemento de conexão entre as demais dimensões; pode-se dizer que a categoria trabalho pedagógico carrega em si a dimensão pedagógica por sua própria natureza. 
Por sua vez, a dimensão política combina o significado objetivo do trabalho pedagógico com o sujeito, na busca de suas perspectivas individuais e coletivas: ser produtivo no mundo do trabalho, conquistar a cidadania e a emancipação social.

\section{Trabalho pedagógico e práxis pedagógica: aproximações}

O trabalho pedagógico, por sua característica dinâmica, modifica-se e adapta-se a diversos fatores constituintes, como, por exemplo: ao nível educativo a que se relaciona (Educação Básica, Educação Profissional ou Educação Superior), ao tipo de instituição (pública ou privada), aos sujeitos a que se destina (crianças, jovens, adultos, trabalhadores, coletivos sociais). Assim, é caracterizado por uma heterogeneidade e, ao mesmo tempo, por uma flexibilidade na adaptação de seus sentidos.

Entender as características adaptativas do trabalho pedagógico, a partir da dinâmica de expansão ou contração ou da prevalência de cada uma das dimensões que o caracteriza, permite, por exemplo, analisar o trabalho pedagógico na Educação Infantil. Nesse nível de ensino e em função dos sujeitos partícipes do trabalho, espera-se teoricamente uma maior ênfase nos aspectos de sociabilidade, dos cuidados de si e dos outros, da organização individual e coletiva. Destacam-se nesse trabalho pedagógico as dimensões pedagógica e social, em detrimento da dimensão política.

Figura 2 - O trabalho pedagógico na Educação Infantil e a valorização das dimensões pedagógica e social

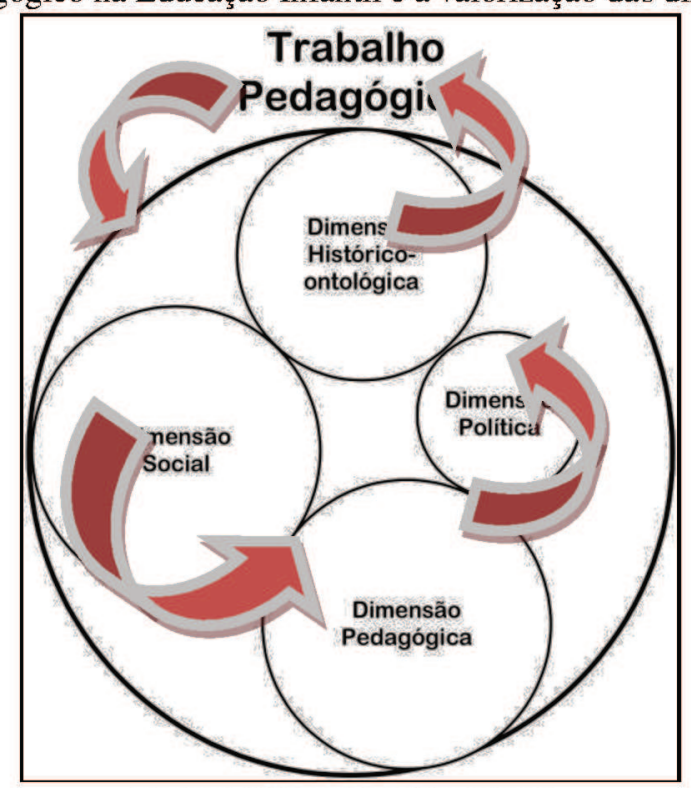

Fonte: Elaborada pelos autores. 
Trata-se de um exemplo hipotético, no qual diversos elementos devem ser pormenorizados e contextualizados, para que as dimensões apresentadas correspondam à realidade do trabalho desenvolvido. No contexto real, podem-se observar negligências, causadas por fatores políticos, ambientais, sociais, etc., que produzem como efeito um trabalho desconexo com a realidade social do estudante, desvalorizando-o ou promovendo um trabalho em sentidos desconexos de sua realidade. Tais situações correspondem, no diagrama proposto, a uma evidente atrofia dimensional.

Para ilustrar a proposição com outro exemplo, pode-se recorrer à suposição de um Ensino Superior em que a ênfase formativa se direcionasse à profissionalização e à inserção do sujeito produtivo no trabalho. Nesse nível de ensino, assim caracterizado, evidenciar-se-ia uma atrofia da dimensão pedagógica, considerando-se que muitos professores não se caracterizariam por serem conhecedores dos aspectos pedagógicos de seu trabalho, dado o fato de serem eles bacharéis. Observarse-ia, como decorrência, nesses casos, forte presença de um ensino tecnicista, o que volatizaria ainda mais a dimensão pedagógica. A dimensão social, nesse caso hipotético, seria dependente de diversos fatores e das próprias características da área do curso em questão (ciências sociais, ciências da saúde, licenciaturas, engenharias, etc.). Genericamente, podem-se expressar as quatro dimensões do trabalho pedagógico no Ensino Superior, nesse exemplo imaginado, da seguinte forma:

Figura 3 - O trabalho pedagógico na Educação Superior, valorização da dimensão política e a atrofia da dimensão pedagógica

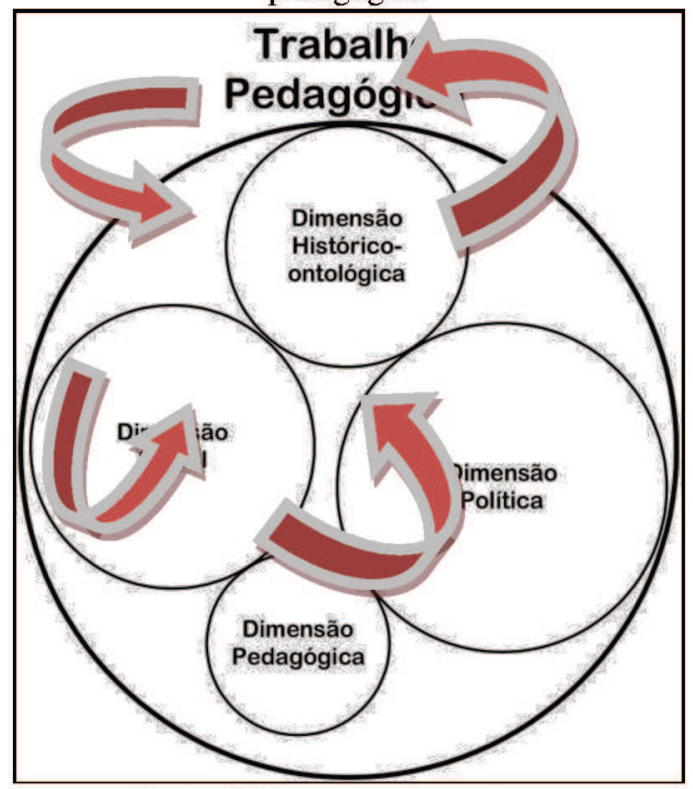

Fonte: Elaborada pelos autores. 
Superar possíveis dificuldades na articulação da multidimensionalidade, que garante a integralização de um trabalho pedagógico, implica também constituí-lo como práxis pedagógica. Na introdução desse artigo, distinguiu-se prática pedagógica de trabalho pedagógico, enfatizando-se o caráter ontológico do trabalho. Prática e trabalho pedagógico diferenciam-se, ainda, em função do modo como operam o "conhecimento". Entende-se a prática como um conjunto de ações objetivadas para um fim imediato, não necessariamente conectadas por um projeto pedagógico coletivo. Na prática, o conhecimento produz-se segundo forma ou técnica específica, o que se diferencia radicalmente de trabalho pedagógico. Neste, tem-se como resultado a produção coletiva do conhecimento (em si e a partir de si), produção na forma unitária entre teoria e prática que resulta em transformação dos sujeitos, ou seja, como práxis pedagógica, na qual

[...] posições teleológicas primárias, que remetem diretamente ao trabalho e à interação com a natureza, e em posições teleológicas secundárias (como a arte, a literatura, a filosofia etc.) mais complexificadas e desenvolvidas que as anteriores, porque supõem a interação entre seres sociais, como práxis interativa e intersubjetiva, mas se constituem como complexos que ocorrem a partir do trabalho em sua forma primária (ANTUNES, 2005, p. 136, grifos do autor).

Nesse sentido, a práxis configura-se através da consolidação de um projeto de autonomia, na ação sobre a cultura e a história dos sujeitos, dos locais onde trabalham, da cultura. Ao propor uma filosofia da práxis, Gramsci reitera a necessidade de atitude, de pensamento que supere o concreto e torne-se crítico, superando, também, desse modo, o senso-comum ou pensamento simples, apesar de partir dele em busca do novo, da crítica efetiva (GRAMSCI, 1981). Em algum momento, há, para os sujeitos, a possibilidade dessa passagem, do imediato para uma proposição crítica de mundo, portanto proposição revolucionária. Gramsci (1981, p. 53) denomina “catarsis" a essa passagem "[...] do momento puramente econômico (ou egoísta-passional) ao momento ético-político, isto é, à elaboração superior da estrutura em superestrutura na consciência dos homens. Isto significa também passagem do objetivo ao subjetivo e da "necessidade de liberdade"'. O peso que sobrecarrega os sujeitos, tornandoos assujeitados, pela catarsis, torna-se possibilidade para libertação, para criação de renovadas condições ético-políticas e de iniciativas. É este "[...] o ponto de partida de toda a filosofia da práxis; o processo catártico coincide com a cadeia de sínteses que resultam do desenvolvimento dialético" (GRAMSCI, 1981, p. 53). Marx (2009, p. 120) já anunciara essa possibilidade de transposição do imediato para a crítica, ao anunciar que os seres humanos transformam as circunstâncias, e, assim, “a coincidência entre a alteração das circunstâncias e a atividade ou automodificação humanas só pode ser apreendida e racionalmente entendida como práxis revolucionária”. 
Uma práxis pedagógica é, dessa maneira, uma associação multidimensional do trabalho pedagógico, reunindo, em suas características, as dimensões histórico-ontológica; pedagógica; social e política. Tais características estão de tal modo imbricadas, ao ponto de resultar na transformação do

real, de modo consciente. É, portanto, mais que prática. Poder-se-ia dizer que é, sob a forma de um projeto planejado por sujeitos organizados em seus coletivos, a reunião de muitas práticas caracterizadas por serem intencionais, sistemáticas, políticas e, claro, pedagógicas, que, articuladas, fundem-se em práxis.

\section{Para finalizar por enquanto...}

Por se acreditar na importância e no amplo valor peculiar da categoria trabalho pedagógico, foi proposta, no presente artigo, uma forma de descrevê-lo. Trata-se de uma representação multidimensional, constituída por quatro dimensões: histórico-ontológica; pedagógica; social e política. Cada uma das dimensões congrega suas características próprias, que lhes conferem valor qualitativo individual. $\mathrm{Na}$ articulação entre as dimensões é que se percebe o sentido amplo e complexo da categoria trabalho pedagógico, que as representações tradicionais não conseguem organizar como um todo adequadamente estruturado. Desenvolveu-se o sentido fundamental de cada dimensão e explorouse a articulação entre as quatro dimensões. Foram apresentados exemplos de análise e representação do trabalho pedagógico por meio desse modelo proposto. Finalmente, na última seção do artigo, desenvolveu-se a relação entre trabalho e práxis pedagógica, potencializando-se a concepção de práxis pedagógica como resultado esperado, considerando-se como possibilidade para tal a ampla exploração das quatro dimensões que integram o trabalho pedagógico.

Notas

${ }^{1}$ Em referência à obra de Paulo Freire. 


\section{REFERÊNCIAS}

ANTUNES, R. L. C. O Caracol e Sua Concha. São Paulo, SP: Boitempo, 2005.

CHAUI, Marilena. Convite à filosofia. São Paulo: Ática, 2012.

FERREIRA, L. S. Gestão do pedagógico: de qual pedagógico se fala? Currículo sem Fronteiras, v. 8, n. 2, p. 176-189, jul./dez. 2008.

FERREIRA, L. S. Trabalho pedagógico. In: OLIVEIRA, Dalila Andrade. et al. Dicionário trabalho, profissão e condição docente. Belo Horizonte: Faculdade de Educação UFMG, 2010.

FREITAS, L. C. Em direção a uma política para a formação de professores. Em Aberto, Brasília, ano 12, n. 54, abr./jun. 1992.

GRAMSCI, A. Concepção dialética da história. Tradução: Carlos Nelson Coutinho. 4. ed. Rio de Janeiro: Civilização Brasileira, 1981.

MARX, K. Ideologia Alemã. 1. ed. São Paulo: Expressão Popular, 2009.

. Manuscritos econômico-filosóficos. 1: ed. 2. reimpr. São Paulo: Boitempo, 2008.

O capital: critica da economia política. Edição digital. São Paulo: Editora Nova Cultural Ltda, 1996, livro I, v. 1.

livro I, v. 1.

O capital: critica da economia política. 31. ed. Rio de Janeiro: Civilização Brasileira, 2013,

SAVIANI, D. História das ideias pedagógicas no Brasil. 3. ed. rev. Campinas, SP: Autores Associados, 2010.

O conceito dialético de mediação na pedagogia histórico-crítica em intermediação com a psicologia histórico-cultural. Revista Germinal: Marxismo e Educação em Debate. Salvador, v. 7, n. 1, p. 26-43, jun. 2015.

. Trabalho e educação: fundamentos ontológicos e históricos. Revista Brasileira de Educação, Rio de Janeiro, v.12, n.34, p. 152-180, jan./abr. 2007.

VÁZQUEZ, Adolfo Sánchez. Filosofia da Práxis. 2. ed. São Paulo: Expressão Popular, 2011.

VEIGA, I. P. A. Inovações e projeto político-pedagógico: uma relação regulatória ou emancipatória?

Cadernos CEDES, Campinas, v. 23, n. 61, p. 267-281, dez. 2003. 


\title{
Educational Work: possibilities for educational praxis and its dimensions \\ Trabajo pedagógico: dimensiones y la posibilidad de la praxis pedagógica
}

\begin{abstract}
The purpose of this paper is to articulate and systematize arguments and understandings of meanings of pedagogical work. It presents a multidimensional model that can better explain this category. It is based on a concept of teaching as work related to the field of pedagogy that focuses on knowledge production. Based on this broad concept, subcategories, and indexes were developed and relationships established between them. Lower level meanings were thus obtained, which when articulated among each other, provide a broader conceptual reworking. This methodological sequence resembles the path taken in writing this text: it begins with a description of the understanding of pedagogical work, based on a model containing dimensions of this particular job and its articulations. Based on this multidimensionality, the paper presents another that it understands is more elaborate as a conceptualization of pedagogical work, in approximation with pedagogical praxis and with the school as context.
\end{abstract}

Keywords: Pedagogical work. Pedagogical praxis. School.

Rodrigo Cardozo Fuentes

E-mail: fuentes.ctism@gmail.com

Liliana Soares Ferreira

E-mail: anaililferreira@yahoo.com.br

\section{Resumen}

Este artículo tiene como objetivo articular y sistematizar argumentos y elaboraciones de sentidos sobre el trabajo pedagógico, con un modelo multidimensional que, en esta perspectiva, se considera que mejor puede explicar esta categoría. Se partió de un concepto de pedagógico como el trabajo relacionado con el campo de la pedagogía que se centra en la producción de conocimiento. Con base en este concepto amplio, fueron identificados subcategorías e índices y establecidas las relaciones entre ellos. Se obtuvo, así, sentidos más pequeños que, articulados entre sí, garantizan una reelaboración conceptual más amplia. Esta secuencia metodológica se asemeja al curso de escritura de este texto: se parte de la descripción de la comprensión del trabajo pedagógico, a partir de un modelo que contiene dimensiones de este trabajo en particular y de sus articulaciones $\mathrm{y}$, con base en esta multidimensionalidad, se presenta otra, más elaborada, como conceptualización de trabajo pedagógico, acercándolo a la praxis pedagógica y teniendo la escuela como contexto.

Palabras clave: Trabajo pedagógico. Práxis Pedagógica. Escuela.

Recebido em: 14/08/2015

Versão final recebida em:

Aprovado em: 27/03/2017 